\title{
Automation, APIs and the distributed labour of platform pedagogies in Google Classroom
}

\author{
Carlo Perrotta (D), Kalervo N. Gulson (D) ${ }^{b}$, Ben Williamson \\ and Kevin Witzenberger (D) ${ }^{d}$
}

${ }^{a}$ Faculty of Education, Monash University, Melbourne, Australia; ${ }^{b}$ School of Education and Social Work, University of Sydney, Sydney, Australia; 'Edinburgh Futures Institute and the Centre for Research in Digital Education at the University of Edinburgh, Edinburgh, UK; ' ${ }^{\text {S }}$ chool of Arts and Media, University of New South Wales in Sydney, Sydney, Australia

\begin{abstract}
Digital platforms have become central to interaction and participation in contemporary societies. New forms of 'platformized education' are rapidly proliferating across education systems, bringing logics of datafication, automation, surveillance, and interoperability into digitally mediated pedagogies. This article presents a conceptual framework and an original analysis of Google Classroom as an infrastructure for pedagogy. Its aim is to establish how Google configures new forms of pedagogic participation according to platform logics, concentrating on the cross-platform interoperability made possible by application programming interfaces (APIs). The analysis focuses on three components of the Google Classroom infrastructure and its configuration of pedagogic dynamics: Google as platform proprietor, setting the 'rules' of participation; the API which permits third-party integrations and data interoperability, thereby introducing automation and surveillance into pedagogic practices; and the emergence of new 'divisions of labour', as the working practices of school system administrators, teachers and guardians are shaped by the integrated infrastructure, while automated Al processes undertake the 'reverse pedagogy' of learning insights from the extraction of digital data. The article concludes with critical legal and practical ramifications of platform operators such as Google participating in education.
\end{abstract}

KEYWORDS

API; automation; datafication; Google; pedagogy; platforms; surveillance

\section{An infrastructure for pedagogy: Google Classroom}

Platforms are now a ubiquitous mode for contemporary interactions, extending beyond commonly known instances like Facebook and Twitter into the mundane fabric of social life and institutions: employed labour, public infrastructure, urban life and, of course, education (Bucher, 2012; Gillespie, 2010; Helmond, 2015; Plantin et al., 2016; Williamson, 2017). Platforms create new connections in a 'global-scale arrangement of planetary-scale computing' (Bratton, 2015, p. 44), with a specific sociotechnical logic that shapes the possibilities of participation. Platforms have myriad definitions, but can be broadly conceived as a combination of new forms of governance, technical elements, 
computation and economics; a platform is a 'standards-based technical-economic system' (Bratton, 2015, pp. 141-142; Vallas \& Schor, 2020).

Our argument in this paper hinges on the proposition that there is a logic specific to educational platforms. Education is undoubtedly influenced by platform logics, but these logics are not entirely deterministic. Instead, they evoke domain-specific 'promissory visions' (Beer, 2018). The promises of granular and socio-emotional personalisation (Williamson, 2019), and machinic neutrality and objectivity in educational assessment (Perrotta \& Selwyn, 2019) are not just imported from other fields where datafication is pervasive; they have been adapted to the specificities of education. This adaptation reflects a distinctive trajectory towards a form of 'computational rationality' that frames educational problems in terms of calculability and prediction (Gulson \& Webb, 2017). We also suggest that the introduction of Google (and its parent company Alphabet), with its search and advertising business model, into education entails a different platform logic than other educational platforms such as learning management systems.

We attempt to substantiate our proposition by exploring a central aspect in educational research and practice: pedagogy. To this purpose, we address the question: what are the features of pedagogic participation configured through a platform logic? The first part of the paper outlines our conceptual framing, comprising the notion of platform logic, and a framing of pedagogic participation within educational platforms. The second part focuses on Google Classroom, which is examined as a prominent case study of platformization in the primary and secondary sectors. We outline Google's increasing role in education through Classroom and propose a model for conceptualising pedagogic participation within it. The model assumes that participation in the Google Classroom is configured through three interrelated processes:

(1) Corporate imprinting: the process through which the platform owner 'sets the scene' in terms of strategy and underlying principles.

(2) Infrastructuring: the development of an application programming interface (API), which allows Google to shape how third-party applications interact with Classroom. We outline four types of integrations between these applications and Classroom: (a) automation, (b) hypervisibility and control, (c) synchronization, and (d) cross-platformization.

(3) The division and automation of labour: the ways in which the infrastructure provides a substratum for pedagogic participation. Here, we focus on the division of labour between teachers, system administrators and guardians, the introduction of elements of automation in the pedagogic environment, and a more insidious 'division of learning' (Zuboff, 2019) between platforms users who generate data without any recompense, and platform controllers who have the technical and epistemic resources to 'learn' valuable insights from those data.

The paper draws on documentary evidence to substantiate its claims but is mainly conceptual. Our argument is that the above processes provide a framework through which a specific infrastructural system seeks to shape participation. In this framework, agency is reconfigured in particular ways: pedagogic decisions become inseparable from technical and administrative decisions; learning becomes interwoven with the development of a platform 
literacy (how to navigate the platform and its API-mediated integrations); and teaching becomes partly automated and distributed.

In the conclusion, we elucidate further our model through the notion of 'double articulation' of the platform pedagogy. This conceptualisation illustrates how the extractive tendencies of Google's business model shape a bidirectional algorithmic pedagogy, as the platform learns constantly from its users, while also creating an infrastructure for partially automated teaching and school management.

\section{Platform logics and participation in education}

Several attempts have been made to categorise the multiple forms of participation mediated by digital platforms, but the concept remains fleeting and ill-defined (Fish et al., 2011; Kelty et al., 2015). A related line of enquiry focuses on how participation is configured through governance strategies and infrastructures that partially structure activities and subjectivities according to digitally encoded logics (Agre, 1994; Decuypere et al., 2014; Introna, 2015; Kitchin \& Dodge, 2011). In this sense, the study of how participation is enabled by platforms, and how it manifests itself, either in normative forms or in idiosyncratic and resistive ones, are distinct empirical endeavours. There is, of course, a key moment when platform logics and human experience come into contact (e.g. Bucher, 2017; Witzenberger, 2018). These encounters require 'traditional' methods based on interviews or other forms of ethnographic observation to be studied, but they are not our focus here. In this article, we are interested in the configuration of participation through infrastructural aspects and their associated logics. Our starting assumption is that platforms reflect the cultural, economic and institutional arrangements within which they are situated, as well as the different strategic goals of the corporations and developers involved in their creation: a gig economy platform like Uber will configure participation differently from an advertising platform like Facebook (Vallas \& Schor, 2020). Therefore, we want to understand how participation in an educational platform is configured in distinctly 'educational' ways.

As we illustrate, Google's platform logic in education is subsumed under two strategic goals: to create an app ecosystem with Google at its centre, and to mould teachers, students, and guardians into future Google users. These goals are pursued through three interrelated strategies: corporate imprinting, infrastructuring, and the automation and the division of labour. Together, these strategies configure a particular type of participation which resembles other forms of platform-mediated participation but is distinctive in its 'pedagogic' scope. Some researchers have already examined the nature of pedagogy in educational platforms such as MOOCs (e.g. Bayne \& Ross, 2014), whilst others have explored how pedagogic labour becomes managerial in response to infrastructural influences (Kelkar, 2017), and their underlying logics: commodification, datafication and personalisation (Van Dijck et al., 2018). While it seems unlikely that teaching as we know it will be radically altered or replaced, a growing concern in educational research is that platforms and automation are rendering the labour of pedagogy more machine-like (Selwyn, 2019). We seek to build on these contributions but simultaneously argue that there is a clear need for research exploring in greater detail the interweaving of platform dynamics, their infrastructural aspects, and pedagogy. 


\section{Developing a conceptual framework for analysing platforms in education}

We locate this paper in the field of infrastructure studies, emphasising the interpretative analysis of 'boring' technical things as a necessary way to understand new forms of sociotechnical power (Star, 1999). The paper draws on relational approaches in infrastructure studies that show how large-scale infrastructures, including platforms, are complex and heterogeneous networks of social, technical, political and economic elements that combine to produce essential services such as energy supply, transport, telecommunications, and that ultimately undergird the organization of economies and societies (e.g. Easterling, 2014). A key empirical concern in platform and infrastructure studies are the logics through which application programming interfaces (APIs) act as 'platform governing instruments' (Van Dijck et al., 2018, p. 35) which specify the common languages and the rules of engagement to which developers and users must adapt (Gray \& Suri, 2019).

Our methodological approach sets off from a 'technographic' analysis of the Google Classroom API. According to Bucher (2018), technography is 'a way of describing and observing the workings of technology in order to examine the interplay between a diverse set of actors (both human and non-human)' (p. 60). Technographic enquiry distinguishes itself from ethnography by concentrating on the suggestive and anticipatory qualities of sociotechnical systems (Galloway, 2006), rather than the meanings attached to those systems by people. Technography can therefore focus on individual algorithms, programmed interfaces or entire platforms, and seeks to reveal not the 'hidden truths' of these systems, but to develop a 'critical understanding of the mechanisms and operational logic of software' (Bucher, 2018, p. 61). As such, technography lends itself to the analysis of secondary sources and technical documentation.

Following this methodological approach, the main aim of this paper is to develop a conceptual framework for analysing platforms in education, drawing on the close analysis of four sources of 'research intelligence':

(1) the terms and conditions, including the privacy policies, of documentation provided by Google for Education to third-party developers and other users.

(2) technical documentation of the Google Classroom API, which we used to identify several third-party applications that integrated into Google Classroom. This work involved creating a typology of integrations including app function, data model and business model.

(3) relevant media articles mentioning Google Classroom, paying particular attention to work that noted the Classroom API.

(4) official guidance for teachers, parents and guardians issued by Google and thirdparty platforms that integrate into Google Classroom (e.g. Savvas Realize, formerly owned by the corporation Pearson).

The analysis that follows is supported by the above sources of evidence.

\section{Corporate imprinting}

One key feature of a platform over other business models is its positioning both ' 1 ) between users, and 2) as the ground upon which their activities occur, which thus givesit 
privileged access to record them' (Srnicek, 2017, p. 44). Google has become one of the world's most prominent providers of educational hardware and software since its first entry into education in 2005. The G Suite of apps was launched in 2006 (first known as Google Apps for Education), followed by Chromebooks in 2011, and Google Classroom (its hub for classroom activities including attendance, classroom discussions, homework, and communication with students and parents) in 2014. Following mass school closures resulting from the Covid-19 pandemic, by April 2020 the company reported 120 million users of G Suite across 250 countries and 54 languages; over 100 million active users of Classroom, doubling its reach from 50 million a month before; and a $60 \%$ share of the market in education computers in the US (De Vynck \& Bergen, 2020). While such statistics do not reveal whether or how Google has reshaped pedagogic participation, they do illustrate its increasing structural dominance over competitors.

Google Classroom and the associated suite of apps are offered free of charge, but this does not mean a precise business strategy is absent (Singer, 2017). Through its educational offerings, Google pursues brand allegiance and familiarisation with its existing infrastructure: teachers and students who become familiar with the Google ecosystem at school will likely continue to rely on it out of school - both its consumer products and enterprise software - thus generating the data from which Google derives most of its revenue. While Google claims none of the data collected through Classroom is used for profiling, it admits that once a user 'steps outside' of the classroom to access any other integrated Google apps, the traditional extractive model applies. In 2015, the Electronic Frontier Foundation formally complained to the US Federal Trade Commission that Google was involved in 'unauthorized collection, maintenance, use and sharing of student personal information beyond what is needed for education' (Cardoza \& Cope, 2015, p. 2).

Many of the extractive features of Google are detectable in the legal specifications of its privacy policies but are concealed by the rhetoric of Google's customer-facing documentation. As Lindh and Nolin (2016) note, 'the rhetorical aim of Google customer-oriented policy documents is to disguise the business model and to persuade the reader to understand Google as a free public service, divorced from marketplace contexts and concerns' (p. 650, original italics). Specifically, they argue, while Google makes strong claims that 'personal data' are not used for advertising or profiling, this does not include the category of 'information Google collects', that is, 'personal information' of the type required for individual profiling, tailoring of content, and personalization of services. By obfuscating its data collection and business practices through such rhetorical moves, 'Google policy allows for a range of surveillance activities' (p. 652).

The extractive tendency of Google configures its peculiar role in the dynamics of pedagogic participation. As Google Classroom's terms of service explain, when a school joins the Google educational ecosystem, it agrees to provide personal information about its students and educators, ranging from usernames and passwords to gender, email, birthday, phone numbers and addresses. This also allows Google to collect information based on the use of its services, including technical data about devices, log information, location information and, of course, cookies and other tracking technologies. Although none of the data collected through its 'core' educational services and products are used for advertising purposes, ads may still reach educational users when they engage with 'additional services' such as YouTube, Google Maps and Blogger (Google, 2018). At the 
same time, Google reserves the right to use the data generated through its educational offerings to refine and further personalise its range of products and services (Google, 2020c). For instance, this would allow Google to use non-personal data collected through the G Suite productivity apps wherever they are being used (i.e. including Google Classroom) to provide or improve other Google products, such as its state of the art AI tools, which have become Google's flagship initiative to cement its competitive advantage in the digital economy.

The official terms of service summarised above seek to position Google as a 'data operator', legally exempting it from the responsibility to establish local protocols for informed consent and privacy. Google is clear that this responsibility lies with local governing bodies and individual schools. This data operator role is, however, contradicted by Google's additional categorisation as a 'school official with legitimate educational interest', in accordance with the US-centric legal framework that underpins its educational offerings, the Family Educational Rights and Privacy Act (FERPA), which means that permission from students and their guardians is legally required only when additional services (such as YouTube) are offered, but not compulsory when a school shares educational records with Google.

As far as Google Classroom is concerned, the tendencies towards pervasive data extraction and surveillance are moderated by some legal constraints, but still operate indirectly in ways that benefit the overall revenue model. In this sense, Google's positioning as a data operator is self-serving and problematic, but entirely consistent with the platform logic of putting in place a flexible template, and then letting users and third-party developers put in the labour and take care of the complexities. At the same time, Google's self-appointed role as school official is entirely accurate, as through the very same platform logic that exonerates it, Google implicitly advocates its own non-neutral view of pedagogy, that is, a normative set of expectations about how teachers teach and students learn, accompanied by technical requirements which govern how additional 'educational' functions are integrated into the classroom experience. This pedagogic vision is materialised literally coded - through a proprietary software infrastructure: the Google Classroom API, the second component of our concept of pedagogic participation.

\section{Infrastructuring: Google Classroom API}

On June $29^{\text {th }}, 2015$, during the International Society for Technology in Education (ISTE) conference in Philadelphia, Google officially launched its Classroom API. Jonathan Rochelle, Google's former director of product for education, showcased it as a framework to connect developers, teachers, and students. The key strategic aim behind the API was to further Google's services and infrastructure into education, creating an ecosystem of third-party apps built on the foundation of Google's powerful and scalable cloud. Discussing the launch during an interview with a public sector media outlet, Rochelle was reported saying 'it fits so well into our strength and ease of deployment. It's definitely much simpler than having the servers in the school, that's like a no-brainer these days. This hits administrators and the school district and school boards as something really powerful' (Shueh, 2015 para. 9).

The launch of the Google Classroom API signalled a clear evolution in Google's education strategy, from simply providing a suite of productivity tools to offering an 
'essential development infrastructure for building software' (Gerlitz et al., 2019 para. 3), which allows Google to monitor and regulate how data are being exchanged, and how functionalities and their associated practices are integrated in the Classroom experience. Before examining the specifics of Google Classroom API, it is perhaps helpful to provide an overview of APIs in general.

APIs are a central integrative mechanism for platforms. They are formal collections of programming conventions and data restrictions that allow external applications to integrate into a platform (Helmond, 2015), and provide interoperability in distributed computing environments (Snodgrass \& Soon, 2019). Thanks to the mediation of APIs, third-party entities (e.g. small developers, large vendors, and service providers) are enrolled in platforms as a source of innovation, while 'end-users' and their interactions become sites of data extraction. Therefore, 'an API can be seen as both an entry point into the black box of a particular computational service, but also as a clearly demarcated barrier towards other possible exchanges with this service' (Snodgrass \& Soon, 2019 n.p.). APIs are therefore the 'grammar' that shapes, to an extent, participation in platforms; a grammar that frames actions and interactions through a form of anticipatory logic. When an API is developed, its creators are required to 'anticipate' scenarios where endusers, devices and multiple types of data interact in (mostly) pre-defined ways. Such 'ontological work' is performed by abstracting complex social relationships in the pursuit of commensurability and algorithmic efficiency. For example, Facebook's Social Graph API performs such work by converting people and their manifold social interactions (likes, updates, histories etc.) into always-on and always-traceable 'objects' endowed with economic viability by virtue of 'algorithmic architectures that dynamically constitute certain forms of social practice around the pursuit of visibility' (Bucher, 2012, p. 2).

Consistent with this broad model, Google Classroom's API actively configures pedagogy as a controllable activity and the classroom as a programmable space. Firstly, the tried and tested mechanisms and structures of formal schooling (classrooms, coursework, student submissions and the asymmetrical relationship between teachers and students) are abstracted into a predefined template for participation. Secondly, the API acts as a bridge between Classroom and third-party integrations. The API itself is not for users. It is the medium through which applications or software communicate with each other. The API enables modularity by allowing a 'plug and play' approach, whereby third-party apps and services can be slotted in seamlessly. In doing so, Google actively outsources the task of expanding the platform functionalities, since it only provides a framework through which external developers and providers will 'enrich' the classroom experience, as long as they remain aligned with the overarching data ontology. These can range from simple share buttons on websites to fully synchronized student and management information systems.

At launch in 2015, around 20 educational content and tool providers could be integrated through the API. As of 2020, this number is in the hundreds. Google provides an example of 50 applications on its Google Classroom landing page (Google, 2020a). While the official guidelines and the API itself target developers, the Google Classroom landing page advertises the platform to educators. Many other third party and in-house applications can integrate with Google Classroom through share buttons or data synchronization, but the 50 endorsed third-party integrations are benchmark examples of what Google values as ways to use its API infrastructure. These advertised integrations 
function as both a message to developers about the types of integrations Google seeks and values, and to show educators its benefits beyond its core functions: from interactive quizzes, to student information systems, content-based platforms, surveillance applications, and performance tools. Of these 50, only four are not of commercial nature but are instead funded through government grants, private foundations, and volunteer work. Only one third-party integration is open source. The remaining integrations are based on a subscription-financing model.

The way in which Google Classroom is embedded into the wider G Suite makes it difficult to draw a clear line between where one environment ends, and another begins. This becomes apparent with third-party integrations developed to draw out and aggregate information across the entire $\mathrm{G}$ Suite range, such as plagiarism tools that embed into Google Docs and extend control beyond Google Classroom. Likewise, some third-party integrations offer attendance monitoring and automated Student Information System (SIS) updates by accessing the log-in credentials of users within Google Meets.

By analysing the 50 endorsed third-party platform integrations, we developed a taxonomy of four different types of integrations according to their main function (there are significant overlaps between categories, but it is a useful heuristic). The types of integrations are: (a) automation; (b) hypervisibility and control, (c) synchronization, and (d) cross-platformization.

Automation describes integrations that automatize classroom processes, tasks and practices ranging from automated grading, to anti-cheat software, the personalization of stock content towards individual students, automated student feedback and content filtering. Automation also features heavily as a secondary function within synchronized management and surveillance systems. Student management systems often feature integrations for automated attendance monitoring, while surveillance systems can automatically block content or notify teachers or parents about suspicious behaviour. Most integrations come in the form of add-ons to the platform either directly through the Classroom API or other G Suite APIs.

The second main function of third-party integration is synchronization, including student (SIS) and management information systems (MIS) that enable a full synchronization with Google Classroom. These integrations automate the generation of student profiles, creation of courses, allocation of students to courses, synchronize calendars amongst staff, or retrieve course or assignment grades from Classroom and copy them into the school-wide administration tool.

Hypervisibility refers to integrations that make interactions between students and staff with Google Classroom visible to others. These extensions enable surveillance and automated control functions via extensive and intricate data collection, making interactions with the system visible in ways that exceed human perception. These apps feature content control filters, student behaviour and platform interaction analytics, screen viewing, browser tab control, device lockdown, automated attendance reports, suicide prevention, and plagiarism checkers. Hypervisibility is not limited to the surveillance of students but extends to staff through advance platform usage analytics. There is a hierarchy of who can view user profiles and data: students are monitored by teachers, guardians, and software, but at the same time many applications allow school administrators to monitor teachers. Potentially districts could use the same procedure to monitor schools. 
The fourth function of third-party integration is cross-platformization. This feature describes other platforms or websites that can link content between Google Classroom and a share button or a single sign on to identify users through the API. The main applications in this category are either aimed at teachers to upload, download, and share teaching material via Google Classroom, or for students to access or create content on third-party websites.

\section{Division and automation of labour in Google Classroom}

In this section, we continue to follow our technographic approach by examining in detail the configuration of pedagogic participation within Google Classroom. This analysis constitutes the third element of our conceptual framework, taking the form of a 'division of labour' structure, represented below as a typified sociotechnical flow where the API logic shapes the actions of administrators, teachers, and guardians.

The system administrator. The API-mediated participation flow of Google Classroom begins with the system administrator, who exercises a distinct form of power by regulating the authentication of users and the integration of apps and external platforms from third parties. Thus, system administrators make key decisions about the circulation of data from and to the Classroom (Google, 2020d). Through an 'admin console', administrators can allocate and verify teaching roles and regulate user engagement with external systems, controlling how data in a domain is shared (Google, 2020e). System administrators authorise institution-level integrations that link Google Classroom with external learning management systems, such as Savvas Realize (formerly owned by Pearson). Once an external system like Realize is authorised on Google Classroom, the two platforms begin to share data (Savvas, 2018). Additional administrator-level decisions include device management (the ability to approve and block registered devices, and to delete all data stored on them), and the choice of a data region policy, which would allow the system administrator to select a geographic location for the educational records collected through the platform (US or Europe, each with their different privacy frameworks). Finally, administrators regulate home access, allowing teachers to share information with guardians through email summaries about missing assignments, class activities and homework. In August 2020 Google announced a range of new tools for administrators, including accessing audit logs, engagement metrics and data dashboards in order to monitor activities and participation of both teachers and students in Classroom, plus moderation tools for tracking student and teacher interactions in Google Meet sessions (Google, 2020g). These examples are crucial from an infrastructure point of view, and configure the pivotal role and capacity of the system administrator in the mechanics of Google Classroom: someone strategically positioned at key intersections and bottlenecks, exercising a noticeable degree of authority that contributes to the enactment of a programmable pedagogy.

The teacher. The labour of teachers in the Google Classroom must conform to the administrative constraints instantiated through the API and is partly shaped by the affordances of the platform and its integrations. Together, these constraints and affordances require teachers to enact new practices to coordinate effectively with the platform and introduce elements of automation in the pedagogic environment. The most likely scenario begins with the use of Google apps to coordinate and assess student work. In the context of literacy and writing, for instance, a teacher can use Google Docs in conjunction with 
Originality Reports, a plagiarism detection service that automatically compares student assignments with content parsed by Google's search engine (billions of web pages and millions of digitized books), flags instances of copying, and suggests citations to ensure 'academic integrity', as well as stylistic and grammar improvements. In this way, the AI-based aspects of Google search are added on to the architecture of Classroom, performing automated labour on behalf of the teacher. Based on these partly automated processes, teachers will assemble remedial plans for students choosing from a range of available options. If Savvas Realize is integrated, they will be able to quickly deploy ready-made and structured sequences of literacy development (e.g. about critical reading skills and note-taking for plagiarism prevention), while providing access to digital texts directly through the platform (Savvas, 2020). These plans are easily shared with guardians.

The guardian or parent. The increasingly important role of guardians in the Google Classroom, as evidenced by a growing literature of official and unofficial guidance (e.g. Google, 2020g), is a clear indication of their formal recruitment within the flow of platformmediated participation. The home-schooling 'boom' spurred by the COVID-19 pandemic in 2020 brought into stark relief the extent to which guardians are expected to take over aspects of homework and motivation management - always in keeping with the grammars of action established by third-party apps and the platform itself. For example, Google launched a Tech Toolkit for Families and Guardians on using G Suite, Classroom, and integrated apps for home learning (Google, 2020h). Following the participation flow delineated thus far, guardians are co-opted through formal channels and involved in a model of remedial intervention that straddles two proprietary platforms (Google Classroom and Savvas Realize). Once coopted, they become integral components of a partially automated pedagogic process where multiple literacy 'solutions' are mobilised. These may include a 'fully automated assessment tool that uses artificial intelligence and voice technology to measure reading abilities', a 'digital library that offers a curated collection of 3,500+ high-quality eBooks', and 'virtual book bags' that can be accessed anywhere and anytime (Savvas, 2020). In order to function, this crossplatform and semi-automated apparatus for remedial literacy relies on home access and distance learning plans, which in turn demand guardians to set up devices for home use. Guardians are therefore encouraged to use additional Google services like Family Link, in order to supervise students' accounts and set up their devices (Google, 2020b). Through infrastructure-mediated encouragements and expectations, the platform logic is thus extended to the home environment, requiring guardians to take on several duties relating to engagement, coordination, and supervision.

The shadow labour. The final piece in the Google Classroom participation puzzle is, at the same time, the most opaque and the most significant from a political-economic point of view. We refer to the participation, or indeed the labour, demanded by the algorithmic 'shadow text', that is, the hidden data aggregations gathered from personal and public action that are only visible to elite analysts or to automated analytical software (Zuboff, 2019). The shadow text is the result of another problematic division - a 'division of learning' between experts who can 'learn' to analyse data, and thereby 'learn' insights from it, and those whose data are extracted. Because 'surveillance capitalism' has access to both the 'material infrastructure and expert brainpower' (Zuboff, 2019, p. 187) to transform human experience into data and wealth, a narrow band of 'privately employed computational specialists, their privately owned machines, and the economic interests for whose sake they learn' (Zuboff, 2019, p. 190) has become a key source of knowledge over human affairs, able to learn from the data in order to 
intervene in society in new ways. Zuboff further argues that automated 'machine learning' has been elevated as the key source of knowledge and learning under surveillance capitalism, with humans even learning to 'emulate the superior learning processes of the smart machines' (Zuboff, 2019, p. 414).

Drawing on Zuboff's analysis, we therefore distinguish between the façade of Google Classroom, its readable and actionable interface engineered to facilitate a particular form of coded pedagogy, and the underlying text of algorithmic surveillance, which is hidden from view and accessible only to Google's epistemic elites, who alone have the expertise and the technological machine learning resources to decode it. This distinction between a publicfacing text and a shadow text is a helpful heuristic to help interrogate the fissures and inequalities that beset the divisions of labour in Google Classroom. Indeed, not only is the shadow text the closely guarded domain of data science and artificial intelligence, but also an abstracted field of labour exploitation in the service of a 'reverse pedagogy', where the platform learns from its users. In this field, all those categorised as platform users (teachers and students) are involved in a laborious relationship with Google, as interactions deliver training data for its proprietary AI. In this sense, every click has the potential to deliver value, which is extracted by Google to refine its commercial productivity tools. The key issue is that user data collected from the G Suite 'core services' appear to be restricted for use in providing those core services, but there is a leaky pipe when users also access other services, as illustrated in the section on Google as the platform proprietor.

It would be inaccurate to claim that the entirety of Google - an organisation employing over 100,000 people - is single-mindedly intent on the exploitation of personal data. However, in the dominant business models in the platform economy, a rhetoric of openness and freedom-to-use conceals 'opacities that platform proprietors manage in their own interest' (Mackenzie, 2019, p. 5). Through these opacities, enabled by a sprawling apparatus of algorithms and specialist knowledge, digital platforms turn data into intangible assets, channelling them along financial circuits and subjecting them to capitalisation. As noted by Birch et al. (2020), the mechanism through which data are turned into assets is a futurefacing undertaking based on expected rather than current revenues. In this sense, Google's extractive tendencies in education acquire a mission-critical purpose that transcends the tensions and disagreements likely to exist within its organisational structure. Similarly, the moulding of Classroom users into datafied Google users represents a corporate 'long game' entirely consistent with its overall strategic outlook.

\section{Conclusion: the double articulation of the platform pedagogy}

In this article, we have examined Google Classroom as an exemplar of platformized infrastructure that shapes a specific form of pedagogic participation. The three main sociotechnical components of pedagogic participation in Google Classroom are: a) the role of Google, the platform proprietor, in establishing the strategic outlook and the 'rules of the game'; b) the various forms of integration enabled by a proprietary API, which simultaneously brackets and extends pedagogy; and c) the multiple divisions of labour which are enabled by the platform dynamics, and upon which the platform as a whole depends.

We situated this article in the literature on infrastructure-mediated and platformmediated participation, but wish to reiterate that our chief claim relates to the distinct educational - indeed pedagogic - ramifications of the platform logic, which are still largely 
understudied in the educational research literature. A more nuanced and discipline-specific language is needed 'to examine platforms beyond simply acknowledging that they shape participation' (Gillespie, 2014 as cited in Clark et al., 2014, p. 1447). We agree that we need more precise discussions about the types of platforms, their underlying operational protocols, the legal frameworks, the commercial strategies, the types of users, and ultimately the multiple types of engagement that all of the above enables or impairs.

Our contribution can be summarised by the notion of a 'doubly articulated pedagogy', which emerges in Google Classroom because of the three components we examined. The first articulation is the off-loading of aspects of educational practice onto apps and other platforms. This signals the fragmentation and the automation of pedagogic participation, shaped by the infrastructure (the Classroom API) and by the specialised technical decisions required to coordinate it. The main consequence is that educators can be easily excluded from discussions about what gets integrated and authorised, how data are collected, and how to establish and maintain licensing relationships with third-party providers of pedagogic integrations, which tend to be delegated to system administrators. The integration of functions into Google Classroom becomes a modular and decoupled process, with multiple sites of control that often exclude teachers and students. This separation between administrative decisions and educational delivery is politically charged insofar as it introduces a sociotechnical power dynamic into the educational context. This dynamic is potentially problematic because it is not the result of a negotiation, but an imposed sociotechnical structure: 'APIs are infrastructural just as they also impose structures and parameters of various kinds, both on the data being exchanged, as well as those who use or come into contact with these exchanges' (Snodgrass \& Soon, 2019 n.p.).

As pedagogy becomes fragmented and enframed within API-dependent power structures, it is additionally altered through 'plug and play' integrations, various forms of automation, and emerging divisions of labour. Our analysis of 50 API-mediated relations reveals a growing landscape of integrations that illuminate how multiple features, practices and relations between teachers and students can be 'slotted in' and automated, as long as they are consistent with the data ontology determined by the functions and methods of the API. The introduction of automation in the pedagogic environment does not eliminate teachers' labour, but reconfigures it by generating new tasks that require teachers to synchronise effectively with the platform, and by slowly but perceptibly shifting their efforts from actual teaching to the 24/7 coordination, moderation and facilitation of student engagement. In this sense, the pedagogy of teachers and students, understood as a form of educational and developmental agency, is becoming equated with pedagogy in the use of platforms, e.g. signing on, assigning tasks, looking for tasks, submitting items, moderating interactions in the classroom 'stream' (Google Classroom's equivalent of Facebook's Timeline) and so forth. Eventually, this platform pedagogy could change the spatial and temporal aspects of schooling - where the classroom exists and what proximity and immediacy mean - as it extends to the home context, where parents or guardians may end up performing the labour of distributed responsibility for pupil compliance with the platform.

The second articulation of the platform pedagogy is the algorithmic learning from data. Here, the learning flows from the users to the platform, which continuously gazes back upon them. Indeed, the algorithmic learning is embedded in the Google experience and thus inescapable. It happens in multiple forms and for different purposes. Google collects anonymous usage data to improve its productivity suite and to develop its predictive and adaptive 
technologies (i.e. to train its AI frameworks). As students and teachers leave the platform as part of their mundane interactions, they engage with other apps and platforms which either belong to Google already (e.g. YouTube) or are involved with Google's extractive infrastructure in one way or another. Drawing on Zuboff's notion of shadow text (Zuboff, 2019), we concentrated on the role of teachers and students in this reverse pedagogy, and described their participation as a form of 'shadow labour', whereby every interaction, every written word and every click is 'dragooned as raw material to be accumulated and analysed as means to others' market ends' (Zuboff, 2019, p. 186). Thus, the extractive tendencies of Google's business model shape a bidirectional algorithmic pedagogy, as the platform learns (indeed, machinelearns), while also creating an infrastructure for partially automated teaching and school management.

Popular understandings of pedagogy emphasise its role as a framework for educational praxis, grounded in certain philosophical traditions, such as Dewey's moral philosophy (Dewey, 1909). Pedagogies are therefore theoretical paradigms that underpin practices and values in education. In more prosaic terms, pedagogies are what educators do as part of their jobs, often (but not always) under conditions of employed labour and in specific institutional settings. This more mundane, yet far-reaching connotation of pedagogy is what we investigated in this article. The labour of pedagogy has been often examined in the context of a subtractive dynamic (Biesta, 2017), whereby the influence of regimes of performativity and

managerialism has resulted in a progressive de-professionalisation of teaching, while the encroachment of administrative and accountability-related duties has repeatedly undercut the educational dimension. Against this backdrop, the process of platformization exercises a distinct form of power that shapes and fragments further the nature of pedagogy-as-labour.

What remains, at this point, is the never-easy task of stating some caveats and implications. One thing we omitted in this article is the analysis of misalignments and forms of resistance in the actual manifestations of pedagogic participation. While it is tempting to paint sociotechnical phenomena in absolutist terms, it is also true that people are not simply 'passive subjects, disciplined in linear and unproblematic ways' by technical systems (Kitchin \& Dodge, 2011, p. 19). There is always a tension between

the sociotechnical imaginaries of large corporations materialised in digital infrastructures, and the compromised reality of sub-standard practices, improvisation, subversion, denial and transgression (Selwyn, 2020).

Finally, more pragmatic implications can be derived from our investigation of Google Classroom, chiefly in terms of legal and institutional frameworks to support a more transparent and consensus-based engagement with educational platforms. Firstly, the role of Google (and other platform owners operating in a similar capacity) as a mere data operator needs to be challenged and, ideally, replaced by its unequivocal categorisation as an educational actor with considerably higher responsibilities. This categorisation has important legal ramifications as it would require that Google, like other corporations operating in this sector, takes a clearer stance in its policies about the integration into its platform of capabilities that undermine the confidential treatment of student data in the name of surveillance-based management.

Secondly, there is a strong need for public and policy debate about educational platforms and the home-schooling trend (forced or voluntary). During 2020, it is estimated that between 862 million to 1.6 billion children and young people, half to $90 \%$ of the global student population, were affected by school closures as a result of the COVID-19 pandemic 
(CCSA, 2020). Many of these learners engaged with education from home, using online tools and platforms, with Google Classroom as one of the most prominent. Google considers that Classroom is 'mission control' for many schools, and is increasing the range of features to suit a schooling at home environment, including a student engagement metric (Google, 2020f). It is reasonable to expect that the need for social distancing will continue for the foreseeable future, meaning that elements of online educational provision will need to be maintained to varying degrees, as countries around the world introduce staggered returns to school, spaced classrooms, and bans on large gatherings will continue to be enforced. In such a scenario, it is essential to have a discussion about the labour of platform-mediated homeschooling, its unequal distribution in the household, its sociological and geopolitical stratifications, and the way it reinforces platform logics of datafication and surveillance.

\section{Disclosure statement}

No potential conflict of interest was reported by the authors.

\section{Notes on contributors}

Carlo Perrotta is Senior Lecturer in Digital Literacies in the Faculty of Education, Monash University. He is interested in the sociological and psychological ramifications of digital technology in education. His current research focuses on the social and political accountability of algorithms, automation and artificial intelligence.

Kalervo N. Gulson is a Professor in the School of Education and Social Work, University of Sydney, Australia, and an Australian Research Council Future Fellow. His research investigates whether new knowledge, methods and technologies from the life and computing sciences, including Artificial Intelligence, will substantively alter the processes and practices of education policy.

Ben Williamson is a Chancellor's Fellow at the Edinburgh Futures Institute and the Centre for Research in Digital Education at the University of Edinburgh. His current research focuses on digital technologies and data infrastructures in higher education, and on the role of data science in the production of policy-relevant knowledge.

Kevin Witzenberger is a Scientia $\mathrm{PhD}$ candidate in the School of Arts and Media at the University of New South Wales in Sydney. He researches the automation of governance in education and the potential impact of artificial intelligence on education policy.

\section{ORCID}

Carlo Perrotta (D) http://orcid.org/0000-0003-3572-0844

Kalervo N. Gulson (iD http://orcid.org/0000-0002-3581-9935

Ben Williamson (D) http://orcid.org/0000-0001-9356-3213

Kevin Witzenberger (iD http://orcid.org/0000-0002-7643-701X

\section{References}

Agre, P. E. (1994). Surveillance and capture: Two models of privacy. The Information Society, 10 (2), 101-127. https://doi.org/10.1080/01972243.1994.9960162 
Bayne, S., \& Ross, J. (2014). The pedagogy of the massive open online course: The UK view. The Higher Education Academy. https://www.advance-he.ac.uk/knowledge-hub/pedagogy-massive -open-online-course-mooc-uk-view

Beer, D. (2018). Envisioning the power of data analytics. Information, Communication E Society, 21(3), 465-479. https://doi.org/10.1080/1369118X.2017.1289232

Biesta, G. (2017). The rediscovery of teaching. Taylor \& Francis.

Birch, K., Chiappetta, M., \& Artyushina, A. (2020). The problem of innovation in technoscientific capitalism: Data rentiership and the policy implications of turning personal digital data into a private asset. Policy Studies, 41(5), 468-487. https://doi.org/10.1080/01442872.2020.1748264

Bratton, B. H. (2015). The stack: On software and sovereignty. MIT Press.

Bucher, T. (2012). Want to be on the top? Algorithmic power and the threat of invisibility on Facebook. New Media \& Society, 14(7), 1164-1180. https://doi.org/10.1177/1461444812440159 Bucher, T. (2017). The algorithmic imaginary: Exploring the ordinary affects of Facebook algorithms. Information, Communication E Society, 20(1), 30-44. https://doi.org/10.1080/ 1369118X.2016.1154086

Bucher, T. (2018). If . . then: Algorithmic power and politics. Oxford University Press.

Cardoza, N., \& Cope, S. (2015). FTC complaint and request for investigation, injunction, and other reflief. Electronic Frontier Foundation. https://www.eff.org/files/2015/12/01/ftccomplaintgoogleforeducation.pdf

CCSA. (2020). How COVID-19 is changing the world: A statistical perspective. Committee for the Coordination of Statistical Activities. https://unstats.un.org/unsd/ccsa/documents/covid19report-ccsa.pdf

Clark, J., Couldry, N., De Kosnik, A. T., Gillespie, T., Jenkins, H., Kelty, C., Papacharissi, Y., Powell, A., \& van Dijck, J. (2014). Participations| Part 5: PLATFORMS. International Journal of Communication, 8(Forum), 1446-1473. https://ijoc.org/index.php/ijoc/article/view/2905

De Vynck, G., \& Bergen, M. (2020). Google classroom users doubled as quarantines spread. Boomberg. Retrieved September 11, 2020, from https://www.bloomberg.com/news/articles/ 2020-04-09/google-widens-lead-in-education-market-as-students-rush-online

Decuypere, M., Ceulemans, C., \& Simons, M. (2014). Schools in the making: Mapping digital spaces of evidence. Journal of Education Policy, 29(5), 617-639. https://doi.org/10.1080/ 02680939.2013 .865081

Dewey, J. (1909). Moral principles in education. Project Gutenberg. http://www.gutenberg.org/ ebooks $/ 25172$

Easterling, K. (2014). Extrastatecraft: The power of infrastructure space. Verso Books.

Fish, A., Murillo, L. F. R., Nguyen, L., Panofsky, A., \& Kelty, C. M. (2011). Birds of the internet. Journal of Cultural Economy, 4(2), 157-187. https://doi.org/10.1080/17530350.2011.563069

Galloway, A. R. (2006). Gaming: Essays on algorithmic culture. Univ Of Minnesota Press.

Gerlitz, C., Helmond, A., van der Vlist, F. N., \& Weltevrede, E. (2019). Regramming the Platform: Infrastructural relations between apps and social media. Computational Culture, 7(7), 3-43. http://computationalculture.net/regramming-the-platform/

Gillespie, T. (2010). The politics of 'platforms'. New Media \& Society, 12(3), 347-364. https://doi. org/10.1177/1461444809342738

Gillespie, T. (2014). The relevance of algorithms. In T. Gillespie, P. Boczkowski, \& K. Foot (Eds.), Media technologies: Essays on communication, materiality, and society (pp. 167-194). MIT Press.

Google. (2018). G suite for education (online) agreement. Retrieved September 03, 2020, from https://gsuite.google.com/terms/education_terms.html?_ga=2.91395482.1259812913. 1501530839-1800684438.1499263309

Google. (2020a). Apps that work \#withClassroom. Retrieved September 03, 2020, from https://edu. google.com/intl/en_au/products/classroom/apps/?modal_active=none

Google. (2020b). Best practices for family engagement. Retrieved September 03, 2020, from http:// services.google.com/fh/files/misc/bestpracticesfor_familyengagement.pdf

Google. (2020c). G suite for education privacy notice. Retrieved September 03, 2020, from https:// gsuite.google.com/terms/education_privacy.html 
Google. (2020d). Google classroom API-authorizing requests. Retrieved September 03, 2020, from https://developers.google.com/classroom/guides/auth

Google. (2020e). Google classroom API -manage teachers and students. Retrieved September 03, 2020, from https://developers.google.com/classroom/guides/manage-users

Google. (2020f). More details on what's coming to meet and classroom. Retrieved September 03, 2020, from https://blog.google/outreach-initiatives/education/the-anywhere-school-meetclassroom-updates/

Google. (2020g). Teach from anywhere - giving teachers and families the tools and tips they need to help keep students learning. Retrieved September 03, 2020, from https://teachfromanywhere. google/intl/en/

Google. (2020h). Tech Toolkit for Families and Guardians Retrieved 3/09/2020, from http:// services.google.com/fh/files/misc/techtoolkit_familiesandguardians.pdf

Gray, M. L., \& Suri, S. (2019). Ghost work: How to stop silicon valley from building a new global underclass. Eamon Dolan/Houghton Mifflin Harcourt.

Gulson, K. N., \& Webb, P. T. (2017). Mapping an emergent field of 'computational education policy': Policy rationalities, prediction and data in the age of artificial intelligence. Research in Education, 98(1), 14-26. https://doi.org/10.1177/0034523717723385

Helmond, A. (2015). The platformization of the web: Making web data platform ready. Social Media + Society, 1(2), 1-11. https://doi.org/10.1177/2056305115603080

Introna, L. D. (2015). Algorithms, governance, and governmentality: On governing academic writing. Science, Technology $\mathcal{E}$ Human Values, 41(1), 17-49. https://doi.org/10.1177/ 0162243915587360

Kelkar, S. (2017). Engineering a platform: The construction of interfaces, users, organizational roles, and the division of labor. New Media E Society, 20(7), 2629-2646. https://doi.org/10.1177/ 1461444817728682

Kelty, C., Panofsky, A., Currie, M., Crooks, R., Erickson, S., Garcia, P., Wartenbe, M., \& Wood, S. (2015). Seven dimensions of contemporary participation disentangled. Journal of the Association for Information Science and Technology, 66(3), 474-488. https://doi.org/10.1002/asi.23202

Kitchin, R., \& Dodge, M. (2011). Code/space: Software and everyday life. MIT Press.

Lindh, M., \& Nolin, J. (2016). Information we collect: Surveillance and privacy in the implementation of google apps for education. European Educational Research Journal, 15(6), 644-663. https://doi.org/10.1177/1474904116654917

Mackenzie, A. (2019). From API to AI: Platforms and their opacities. Information, Communication $\mathcal{E}$ Society, 22(13), 1989-2006. https://doi.org/10.1080/1369118X.2018.1476569

Perrotta, C., \& Selwyn, N. (2019). Deep learning goes to school: Toward a relational understanding of AI in education. Learning, Media and Technology, 1-19. https://doi.org/10.1080/17439884. 2020.1686017

Plantin, J.-C., Lagoze, C., Edwards, P. N., \& Sandvig, C. (2016). Infrastructure studies meet platform studies in the age of Google and Facebook. New Media \& Society, 20(1), 293-310. https://doi.org/10.1177/1461444816661553

Savvas. (2018). Where technology and learning meet. Savvas. Retrieved September 03, 2020, from https://www.savvas.com/index.cfm?locator=PS31Wk

Savvas. (2020). Reading spot.Savvas, Retrieved September 03, 2020, from https://www.savvas.com/ index.cfm?locator=PS38T7\&PMDbSiteId=2781\&PMDbSolutionId=6724\&PMDbSubSolutionId= $\&$ PMDbCategoryId=3289\&PMDbSubCategoryId=\&PMDbSubjectAreaId=\&PMDbProgramId= 160861

Selwyn, N. (2019). Should robots replace teachers? AI and thefuture of education. Polity. Selwyn, N. (2020). Just playing around with Excel and pivot tables - the realities of data-driven schooling. Research Papers in Education, 1-20. https://doi.org/10.1080/02671522.2020.1812107 Shueh, J. (2015). Google classroom update opens platform to education developers, publishers. Government Technology. Retrieved June 01, 2020, from https://www.govtech.com/education/ Google-Classroom-Update-Opens-Platform-to-Education-Developers-Publishers.html 
Singer, N. (2017). How Google took over the classroom. The New York Times. Retrieved June, 2020, from https://www.nytimes.com/2017/05/13/technology/google-education-chromebooksschools.html

Snodgrass, E., \& Soon, W. (2019). API practices and paradigms: Exploring the protocological parameters of APIs as key facilitators of sociotechnical forms of exchange. First Monday, 24(2). https://doi.org/10.5210/fm.v24i2.9553

Srnicek, N. (2017). Platform capitalism. Pollity.

Star, S. L. (1999). The ethnography of infrastructure. American Behavioral Scientist, 43(3), 377391. https://doi.org/10.1177/00027649921955326

Vallas, S., \& Schor, J. B. (2020). What do platforms do? Understanding the gig economy. Annual Review of Sociology, 46(1), 273-294. https://doi.org/10.1146/annurev-soc-121919-054857

Van Dijck, J., Poell, T., \& De Waal, M. (2018). The platform society: Public values in a connective world. Oxford University Press.

Williamson, B. (2017). Learning in the 'platform society': Disassembling an educational data assemblage. Research in Education, 98(1), 59-82. https://doi.org/10.1177/0034523717723389 Williamson, B. (2019). Psychodata: Disassembling the psychological, economic, and statistical infrastructure of 'social-emotional learning'. Journal of Education Policy, 1-26. https://doi.org/ $10.1080 / 02680939.2019 .1672895$

Witzenberger, K. (2018). The hyperdodge: How users resist algorithmic objects in everyday life. Media Theory, (2), 29-51\%V 22. http://journalcontent.mediatheoryjournal.org/index.php/mt/ article/view $/ 56$

Zuboff, S. (2019). The age of surveillance capitalism: The fight for a human future at the new frontier of power. Profile Books. 